\title{
Spectral Indices Accurately Quantify Changes in Seedling Physiology Following Fire: Towards Mechanistic Assessments of Post-Fire Carbon Cycling
}

\author{
Aaron M. Sparks ${ }^{1,2, *}$, Crystal A. Kolden ${ }^{1,2}$, Alan F. Talhelm ${ }^{3}$, Alistair M.S. Smith ${ }^{1,2}$, \\ Kent G. Apostol ${ }^{4}$, Daniel M. Johnson ${ }^{1}$ and Luigi Boschetti ${ }^{1}$ \\ 1 College of Natural Resources, University of Idaho, Moscow, ID 83844, USA; ckolden@uidaho.edu (C.A.K.); \\ alistair@uidaho.edu (A.M.S.S.); danjohnson@uidaho.edu (D.M.J.); luigi@uidaho.edu (L.B.) \\ 2 Idaho Fire Initiative for Research and Education (IFIRE), University of Idaho, Moscow, ID 83844, USA \\ 3 Oak Ridge Institute for Science Education, National Center for Environmental Assessment, \\ US Environmental Protection Agency, Research Triangle Park, NC 277094, USA; atalhelm@uidaho.edu \\ 4 College of Agriculture and Life Sciences, University of Arizona, Payson, AZ 85541, USA; \\ kapostol@gmail.com \\ * Correspondence: spar5010@vandals.uidaho.edu; Tel.: +1-208-885-1009
}

Academic Editors: Diofantos Hadjimitsis, Ioannis Gitas, Kyriacos Themistocleous and Prasad S. Thenkabail Received: 25 April 2016; Accepted: 30 June 2016; Published: 7 July 2016

\begin{abstract}
Fire activity, in terms of intensity, frequency, and total area burned, is expected to increase with a changing climate. A challenge for landscape-level assessment of fire effects, often termed burn severity, is that current remote sensing assessments provide very little information regarding tree/vegetation physiological performance and recovery, limiting our understanding of fire effects on ecosystem services such as carbon storage/cycling. In this paper, we evaluated whether spectral indices common in vegetation stress and burn severity assessments could accurately quantify post-fire physiological performance (indicated by net photosynthesis and crown scorch) of two seedling species, Larix occidentalis and Pinus contorta. Seedlings were subjected to increasing fire radiative energy density (FRED) doses through a series of controlled laboratory surface fires. Mortality, physiology, and spectral reflectance were assessed for a month following the fires, and then again at one year post-fire. The differenced Normalized Difference Vegetation Index (dNDVI) spectral index outperformed other spectral indices used for vegetation stress and burn severity characterization in regard to leaf net photosynthesis quantification, indicating that landscape-level quantification of tree physiology may be possible. Additionally, the survival of the majority of seedlings in the low and moderate FRED doses indicates that fire-induced mortality is more complex than the currently accepted binary scenario, where trees survive with no impacts below a certain temperature and duration threshold, and mortality occurs above the threshold.
\end{abstract}

Keywords: fire; remote sensing; severity; carbon; recovery; mortality

\section{Introduction}

Recent evidence from North America of increased fire activity (intensity, frequency, and total area burned) due to anthropogenic climate change [1-3] underscores the need to improve our understanding of variable fire intensity impacts on ecosystem productivity at local to regional scales. Current assessments of the ecological impacts of fires, termed burn severity, investigate the degree to which an ecosystem has changed due to a fire [4] and typically encompass both vegetation and soil effects [5]. Biomass consumption, vegetation mortality, and soil infiltration/water repellency are field metrics used to quantify fire effects [6,7]. Burn severity at local to regional scales is typically characterized from bi-temporal spectral indices derived from satellite sensor remote sensing data 
that quantify change due to fire effects [6]. These remotely-sensed assessments can provide useful information regarding the areal extent of fires and vegetation cover change. However, current assessments provide little to no direct information regarding the physiological status of trees or other vegetation following fires [8], which is an important factor in determining effects on ecosystem services and post-fire land management planning.

The assessment of burn severity at landscape scales is widely achieved using methods employing spectral indices that use the red and infrared bands of the Landsat satellite sensor series. Differenced indices calculated using pre- and post-fire Landsat scenes are commonly used to improve change detection and visual contrast in burn severity assessments $[9,10]$. Specifically, the differenced Normalized Difference Vegetation Index (dNDVI), the differenced Normalized Burn Ratio (dNBR), and the Relativized differenced Normalized Burn Ratio (RdNBR) have been used to quantify area burned, burn severity, and recovery from continental to individual fire scales [6,10-14]. The majority of recent studies focus on dNBR- and RdNBR-based severity assessment [6,15]. However, dNBRand RdNBR-based severity studies only serve as a proxy for changes in vegetation cover, char, and soils, and do not quantify tree mortality, tree physiological parameters relevant to carbon cycling (e.g., leaf area index, net ecosystem productivity), or recovery of physiological processes in the plants that survive the fire $[6,8,16]$. Importantly, such dNBR- and RdNBR-based severity assessments are not usually reported as quantitative spatial datasets, but rather as qualitative classes with values of unburned to low, moderate, and high severity [6,17]. Recent tree-scale research studies have observed that physiology metrics respond to variation in heat associated with fires [8,18-20]. Coupling fire-physiology observations to landscape-scale remote sensing could help to overcome the limitations associated with current severity assessments and promote quantitative measures that increase our understanding of carbon cycling and mortality post-fire [8].

A prior study [8] provided greater detail on the problems associated with current severity assessment methods. That study [8] proposed that one potential approach to assessing burn severity could be achieved by incorporating biological sciences perspectives through the use of dose-response experiments, where fire radiative energy density (FRED: $\mathrm{MJ} \cdot \mathrm{m}^{-2}$ ) was the dose metric and plant carbon or water processes were proposed as potential response metrics. This proposed mechanistic approach to burn severity has the improved potential to link remote sensing datasets to ecosystem process models. Several other studies have used the FRED methodology as a pathway to characterize fire effects at both plot and landscape scales [21,22]. Increasing FRED doses have been observed to cause significant reductions in leaf-level net photosynthesis in Pinus contorta at four weeks post-fire [8]. This study called for further research to investigate these relations in other species, over a wider range of spectral indices, and at extended temporal scales.

Although the prior study [8] presented a potential framework for improving severity assessments from a mechanistic standpoint, it was only a short communication that did not investigate the potential for spectral indices and remote sensing in detail. The prior study [8] also only presented dNBR and dNDVI as examples, but did not evaluate other spectral indices that are known to have strong linkages with plant physiological function (e.g., the Photochemical Reflectance Index, PRI, [23]). This past study [8] also did not attempt to elucidate what physiological changes in the seedlings were responsible for the observed differences in the spectral indices over time. The earlier study [8] also only considered a single species, Pinus contorta, and a key question produced by their findings was whether the spectral changes associated with the increasing FRED doses would transfer across species.

Here, the main objectives are to build on the prior study [8] and test our hypotheses that, (1) increasing FRED dose leads to increased mortality one year post-fire; and (2) decreasing levels of seedling physiological performance caused by increasing FRED doses can be detected using common spectral indices, such as dNDVI, dPRI, and dNBR (Table 1). We further hypothesized that dNDVI and $\mathrm{dPRI}$ would have the strongest linkages to physiological responses in the seedlings, as these spectral indices have well-documented successes in monitoring photosynthetic activity [24-27]. We tested the performance of $\mathrm{dNBR}$ as it is the most commonly used spectral index in the burn severity quantification 
literature $[6,10,11,13,28-30]$. To address the main objective, we examined how these three spectral indices changed as two physiologically different seedling species responded to increasing FRED levels. We then examined the post-fire trajectories of these three spectral indices for a month following the fires, and then again at one year post-fire.

Table 1. Spectral indices assessed in this study.

\begin{tabular}{cc}
\hline Spectral Index & Formulation \\
\hline NDVI & $\rho_{\text {NIR }}-\rho_{\mathrm{r}} / \rho_{\mathrm{NIR}}+\rho_{\mathrm{r}}$ \\
dNDVI & $\mathrm{NDVI}_{\text {prefire }}-\mathrm{NDVI}_{\text {postfire }}$ \\
NBR & $\rho_{\mathrm{NIR}}-\rho_{\mathrm{SWIR}} / \rho_{\mathrm{NIR}}+\rho_{\mathrm{SWIR}}$ \\
$\mathrm{dNBR}$ & $\mathrm{NBR}_{\text {prefire }}-\mathrm{NBR}_{\text {postfire }}$ \\
PRI & $\rho_{531}-\rho_{570} / \rho_{531}+\rho_{570}$ \\
dPRI & $\mathrm{PRI}_{\text {prefire }}-\mathrm{PRI}_{\text {postfire }}$ \\
\hline
\end{tabular}

$\rho_{\mathrm{NIR}}=$ sensor near-infrared reflectance, $\rho_{\mathrm{r}}=$ sensor red reflectance, and $\rho_{\mathrm{SWIR}}=$ sensor shortwave infrared reflectance. For PRI, $\rho_{531}$ and $\rho_{570}$ denote reflectance from specific spectral wavelengths $(\mu \mathrm{m})$.

\section{Materials and Methods}

\subsection{Plant Materials}

Details of seedling culture and growing conditions are reported in more detail in a prior study [8]. In total, 36 Larix occidentalis (western larch) and 36 Pinus contorta (lodgepole pine) seedlings were grown in an open-sided greenhouse at the University of Idaho Pitkin Forest Nursery in Moscow, ID, USA, using $3.8 \mathrm{~L}$ pots through two and a half growing seasons under natural light conditions. The Pinus and Larix seedlings were randomly divided into four groups of nine seedlings (control group and three levels of FRED), and kept in the greenhouse except during the fire combustion experiments. For both species, the seedlings averaged a height of approximately $0.6 \mathrm{~m}$.

\subsection{Experimental Fire Setup}

Experiments were conducted at the indoor combustion laboratory associated with the Idaho Fire Initiative for Research and Education (IFIRE). From the fire science literature [31,32], it is well-accepted that the consumption of pure fuel beds of known type, loads, and moisture contents will release predictable amounts of FRED. Using data presented in [33] and following the methods described in [8], we determined the loads $\left(\mathrm{kg} \cdot \mathrm{m}^{-2}\right)$ of dry ( $0 \%$ fuel moisture content) Pinus monticola (western white pine) needles to produce total FRED “doses" of $0.4 \mathrm{MJ} \cdot \mathrm{m}^{-2}$ (low group), $0.8 \mathrm{MJ} \cdot \mathrm{m}^{-2}$ (moderate group), and $1.2 \mathrm{MJ} \cdot \mathrm{m}^{-2}$ (high group). A control group containing the same number of replicates was included that was not exposed to fire. These doses were created to simulate the range of fire behavior typically seen in surface fires across a range of global woodland ecosystems [21,34,35]. The needles used in the current experiment were collected from a Pinus monticola plantation located adjacent to the University of Idaho, and were manually sorted to remove impurities. For each ignition, 1-2 g of 100-proof ethanol was added to the edge of the fuel bed and ignited to provide a uniformly spreading flaming front. Each burn occurred over approximately the same duration regardless of fuel load $(229 \pm 2.1 \mathrm{~s})$ and was considered complete once smoldering combustion had ceased for at least $20 \mathrm{~s}$.

\subsection{Spectral Measurements}

Spectral reflectance was collected from one week prior to the experiments until four weeks post-fire using an ASD FieldSpec Pro spectroradiometer with the mineral probe attachment (Analytical Spectral Devices, Boulder, CO, USA). This spectroradiometer has a spectral resolution of 3 nm between 350-1000 nm and $10 \mathrm{~nm}$ between 1000 and $2500 \mathrm{~nm}$. Spectra were internally processed via linear interpolation to $1 \mathrm{~nm}$ resolution before any calculations were performed. Multiple (three-to-seven) pre-fire spectra were collected from both old (internodal) and new (apical bud) foliage on each 
seedling to create baseline spectral measurements for each tree, where each measurement averaged ten collections from the spectroradiometer. For each non-destructive spectral sample, $\sim 5 \mathrm{~cm}^{2}$ of foliage was positioned between a background object of known reflectance and the mineral probe attachment. The background reflectance was subtracted from each sample. Where possible, post-fire spectra were collected from the same locations as the pre-fire spectra. At 52 and 54 weeks post-fire, some of the trees were harvested for a companion study, leaving fewer trees for spectra collection. The location of the new foliage spectra was coincident with photosynthesis measurements (as described below). Between each seedling, a Spectralon panel calibration measurement was made to enable calculation of reflectance. All spectra were converted into band-equivalent reflectance $[36,37]$ associated with Landsat 8 Operational Land Imager (OLI) (see [38] for specific wavelengths) for the calculation of the Normalized Burn Ratio (NBR: [30]) and the Normalized Difference Vegetation Index (NDVI: [39]). The Photochemical Reflectance Index (PRI: [23]) used the individual wavelengths of 531 and $570 \mathrm{~nm}$. Table 1 outlines each spectral index calculated in this study. Photographs were also taken pre-fire( -1 days) and post-fire $(+1,2$, and 4 weeks) to obtain visual estimates of crown scorch, which was assessed following the methodology in [30]. Specifically, the proportion of the crown volume that is yellow-green or brown is visually compared to the total crown volume.

\subsection{Seedling Physiology Measurements}

To elucidate the potential physiological properties that cause the observed changes in the spectral indices, we draw on data from a related study [20]. That study collected additional seedling physiological metrics and sought to understand the underlying mechanisms associated with mortality and post-fire recovery. More detail of the methods can be found in [20] but the subset of metrics that are used in this study are briefly described here. Light-saturated $\left(1100 \mathrm{mmol} \cdot \mathrm{m}^{-2} \cdot \mathrm{s}^{-1} \mathrm{PPFD}\right)$ gas exchange (photosynthesis) and chlorophyll fluorescence measurements were performed following standard protocols [40,41] using a LI-6400XT and 6400-05 LED light source and conifer chamber (LI-COR, Inc., Lincoln, NE, USA) one day prior to the burns and then at 1, 4, 7, 14, and 28 days following the burns on five randomly-selected plants in each dose group. Water potential was measured following standard protocols [42] at midday at the same sampling intervals as $P_{N}$ using a Model 600 Pressure Chamber (PMS Instruments Company, Albany, OR, USA).

\subsection{Statistical Analysis}

Physiological and spectral differences were compared with ANOVA and, if significant, a Tukey's Honest Significant Difference test (HSD, $\alpha=0.05$ ). Distributional assumptions required for ANOVA were graphically assessed and homogeneity of variances were verified using the Bartlett Test of Homogeneity of Variances [43]. Relationship 'goodness of fit' between dependent and independent variables was assessed using the coefficient of determination $\left(\mathrm{r}^{2}\right)$ and standard error of the estimate (SEE) from regression analysis.

\section{Results}

For both tree species, increasing FRED dose resulted in increasing crown scorch and decreasing physiological performance (Figure 1). We found positive, non-linear relationships between FRED dose and crown scorch at four weeks post-fire (Figure 1b, Pinus: $\mathrm{r}^{2}=0.94$, SEE $=0.10, p<0.001$; Larix: $r^{2}=0.95$, SEE $=0.09, p<0.001$ ). In comparison, we observed negative linear relationships between crown scorch and $\mathrm{P}_{\mathrm{N}}$ at four weeks following the fire (Figure 1c) for Pinus $\left(\mathrm{r}^{2}=0.44, \mathrm{SEE}=2.1, p<0.01\right)$ and Larix $\left(\mathrm{r}^{2}=0.72, \mathrm{SEE}=1.5, p<0.001\right)$. Likewise, significant negative relationships were observed between crown scorch and stomatal conductance (Figure 1d, Pinus: $\mathrm{r}^{2}=0.77, p<0.001$, Larix: $\mathrm{r}^{2}=0.45$, $p<0.01$ ) for both species and leaf water potential for lodgepole pine (Pinus: $\mathrm{r}^{2}=0.56$, SEE $=0.08$, $p<0.001$ ). The dNDVI spectral index had significant positive relationships (i.e., greater deviation from baseline values as crown scorch increased) with crown scorch (data not shown, Pinus: $\mathrm{r}^{2}=0.34$, 
$p<0.001$; Larix: $\mathrm{r}^{2}=0.24, p<0.01$ ). Figure 2 displays example photos of crown scorch for each FRED dose group at four weeks post-fire.

a)

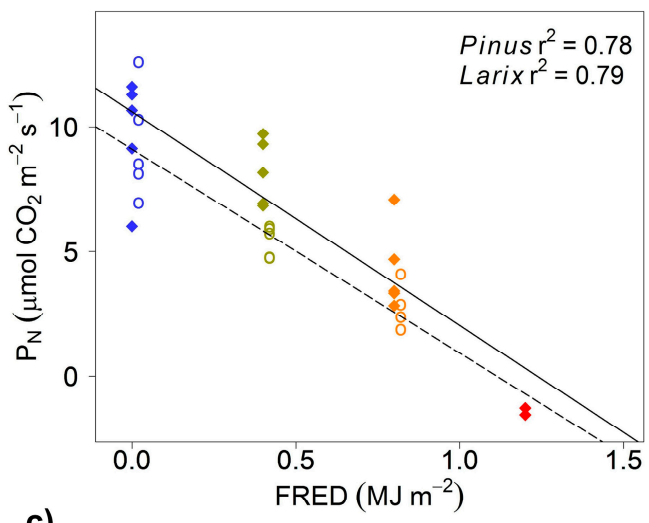

c)

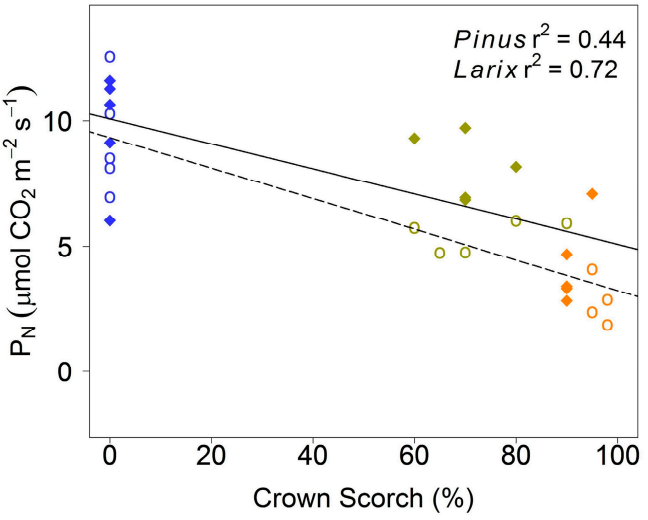

b)

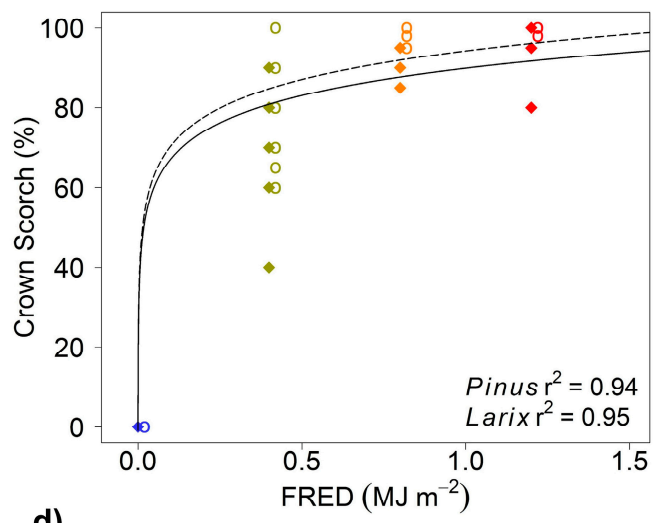

d)

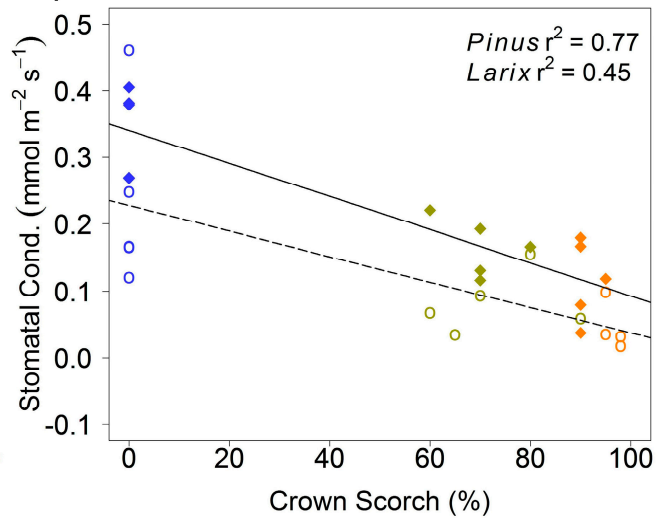

Figure 1. Increasing FRED dose leads to increasing crown scorch and lower leaf physiological performance. Scatterplots display four week post-fire data with colors representing FRED doses: blue $=$ control, yellow $=0.4 \mathrm{MJ} \cdot \mathrm{m}^{-2}$, orange $=0.8 \mathrm{MJ} \cdot \mathrm{m}^{-2}$, and red $=1.2 \mathrm{MJ} \cdot \mathrm{m}^{-2}$, and solid markers representing Pinus and open markers representing Larix. The solid and dotted lines represent predicted values for Pinus and Larix four weeks post-fire, respectively. Sub-plots are as follows: (a) leaf $P_{N}$ predicted from FRED (adapted from [8] to include a comparison with Larix) and (b) crown scorch predicted from FRED; (c) $\mathrm{P}_{\mathrm{N}}$ predicted from crown scorch; and (d) stomatal conductance predicted from crown scorch.

The temporal trajectory of all spectral indices for the high FRED dose seedling group for both species generally displayed a slight increasing trajectory or no trend at all (Figure 3). An exception to this is the decrease in dNBR and dNDVI index values for Larix at three and four weeks post-fire. Several of the Larix produced small leaf buds that initially grew for a few days, but ultimately died. This could explain the slight decrease of spectral index values (toward pre-fire baseline values) of Larix. Both dNDVI and dPRI spectral index values for the low and moderate FRED doses displayed bell-shaped temporal trajectories with values peaking at two weeks post-fire. These values generally decreased at three and four weeks post-fire, possibly indicating partial recovery in both seedling species. The dNBR spectral index did not display as strong of a trend as dNDVI and dPRI in either species. All pre- and post-fire spectral reflectance data are contained within supplemental data (Table S1). At one year post-fire $100 \%$ of the Pinus and $67 \%$ of the Larix seedlings exposed to the $0.4 \mathrm{MJ} \cdot \mathrm{m}^{-2}$ dose survived. However, only $67 \%$ of the Pinus and $50 \%$ of the Larix seedlings exposed to the $0.8 \mathrm{MJ} \cdot \mathrm{m}^{-2}$ dose survived. All seedlings (over both species) exposed to $1.2 \mathrm{MJ} \cdot \mathrm{m}^{-2}$ died within one month post-fire. The mortality of the two Larix seedlings in the low treatment was attributed to a potential interaction associated with poor pre-fire seedling vigor. For the trees that survived 52 and 
54 weeks following the low and moderate intensity fires, all spectral indices returned to, or surpassed, their pre-fire baseline values (Figure 3). Even though some delayed mortality is present one year post-fire, these results still demonstrate a clear dose-response with higher delayed mortality in the larger $0.8 \mathrm{MJ} \cdot \mathrm{m}^{-2}$ dose groups.

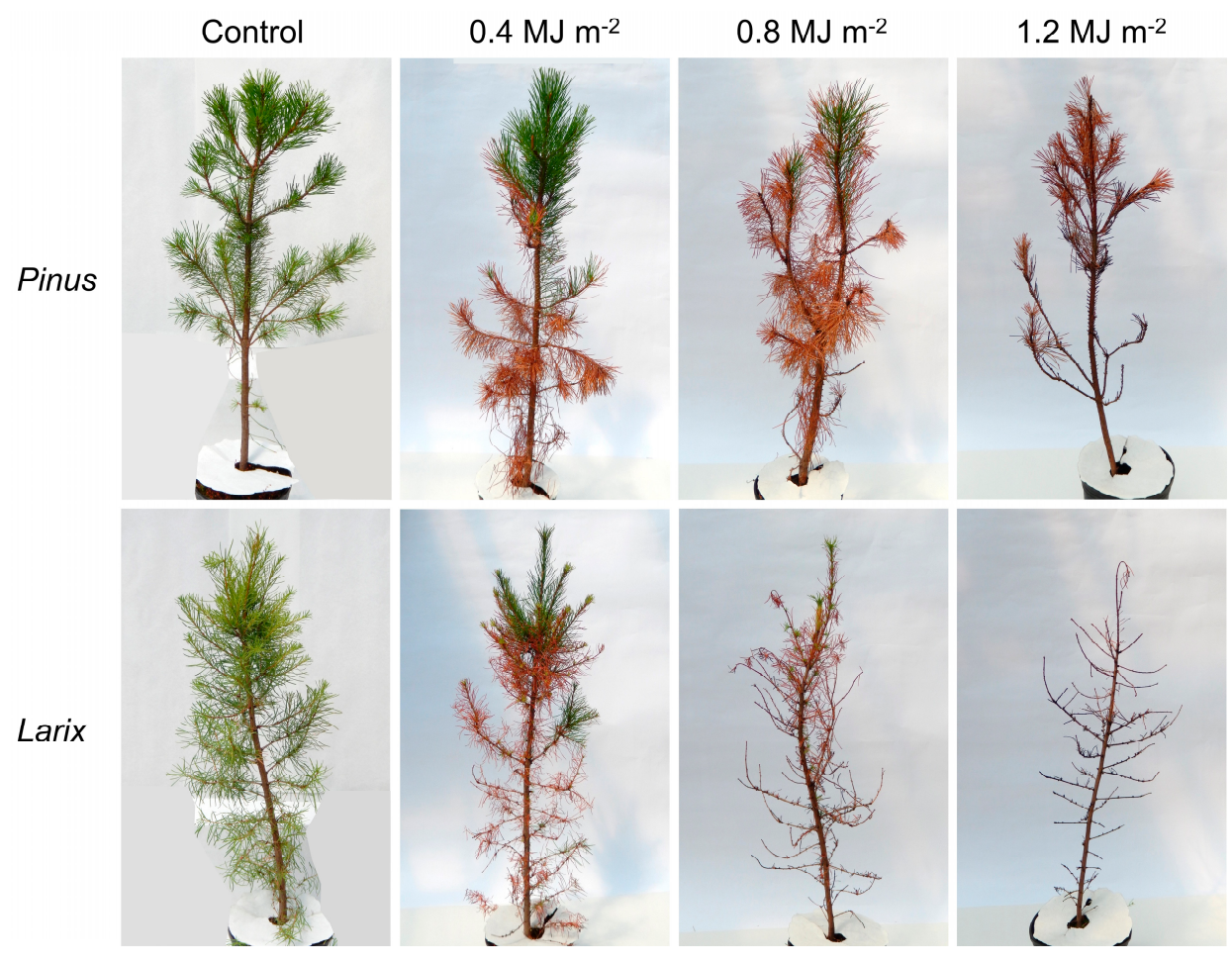

Figure 2. Crown scorch increased with FRED dose for both species. Photographs display overall seedling condition four weeks post-fire.

Higher FRED dose resulted in increasing values (i.e., greater change from pre-fire baseline values) for all three differenced spectral indices across both species (Figure 3). Linear relationships between the differenced spectral indices and FRED were generally strongest (i.e., $\mathrm{r}^{2}>0.50$ and SEE $<0.1$ ) one to two weeks following the combustion experiments. The dNDVI spectral index had the strongest relationships $\left(\mathrm{r}^{2}=0.73-0.85\right)$ for both species at these time periods. The dNBR spectral index had the weakest relationships over this same period $\left(r^{2}=0.53-0.73\right)$.

Although the relationships between the differenced indices and FRED were strongest at 1-2 weeks following the burn, relationships between spectral indices and physiological performance were strongest four weeks post-fire (Figure 4c). Chlorophyll fluorescence was the only exception, where linear relationships were strongest one week post-fire. The dPRI spectral index had the strongest relationship with chlorophyll fluorescence one week post-fire (Pinus: $\mathrm{r}^{2}=0.76, \mathrm{SEE}=0.04, p<0.001$; Larix: $\mathrm{r}^{2}=0.36, \mathrm{SEE}=0.06, p<0.01$ ) for both species (Figure $4 \mathrm{~d}$ ). Linear relationships between the differenced spectral indices and $P_{N}$ were strongest at four weeks post-fire (Figure $4 \mathrm{c}$ ). Among the differenced indices at this time point, $\mathrm{dNDVI}$ had stronger linear relationships with photosynthesis in both species (Pinus: $\mathrm{r}^{2}=0.70, \mathrm{SEE}=2.25, p<0.001$; Larix: $\mathrm{r}^{2}=0.38$, SEE $=2.48, p<0.01$ ) than did dNBR (Pinus: $\mathrm{r}^{2}=0.65, \mathrm{SE}=2.4, p<0.001$; Larix: $\left.\mathrm{r}^{2}=0.03, \mathrm{SEE}=3.12, p=0.57\right)$ or $\mathrm{dPRI}\left(\right.$ Pinus: $\mathrm{r}^{2}=0.60$, $\mathrm{SEE}=2.61, p<0.001$; Larix: $\left.\mathrm{r}^{2}=0.35, \mathrm{SEE}=2.55, p<0.05\right)$. Mean dNDVI values were significantly different $(p<0.001)$ between the control $(-0.016)$ and high $(0.457)$, control and low $(0.172)$, control and moderate (0.209), low and high, and moderate and high FRED dose groups for Pinus. Additionally, mean dNDVI values were significantly different $(p<0.001)$ between the control $(0.027)$ and moderate (0.142), control and high (0.349), low (0.053) and high, and low and moderate FRED dose groups for Larix. 

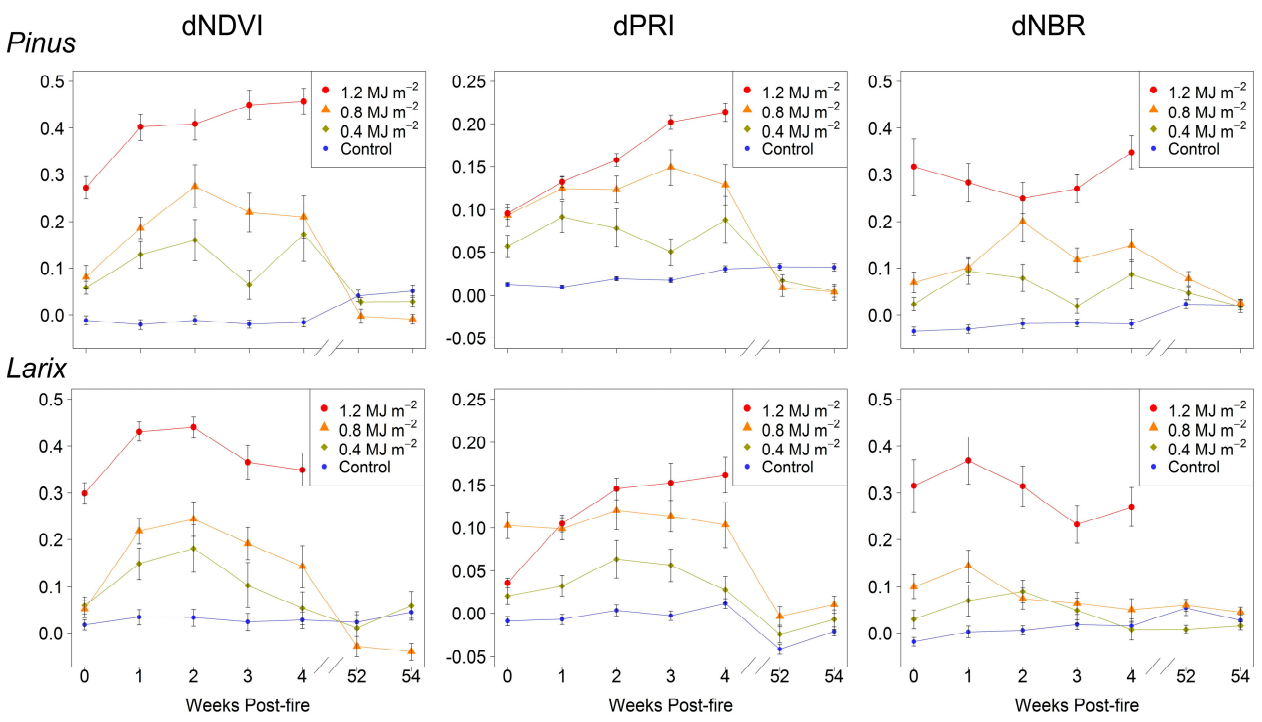

Figure 3. Differenced spectral indices display greater change with increasing FRED dose. Temporal trajectories of the three differenced spectral indices are displayed from one day to four weeks and at 52 and 54 weeks post-fire for Pinus contorta (top row) and Larix occidentalis (bottom row). Error bars represent standard error ( 1 day-4 weeks $n=9,52$ and 54 weeks $n=3-6$ ).
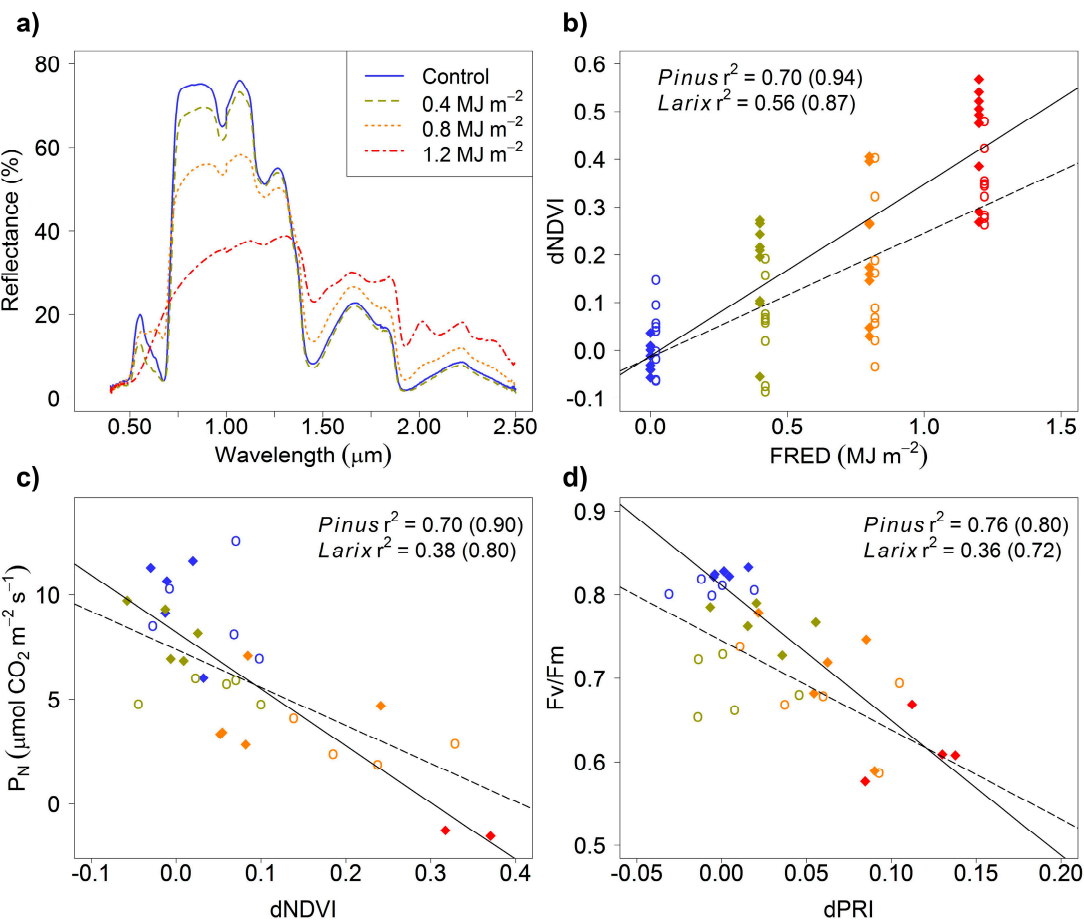

Figure 4. Spectral indices are strongly influenced by FRED dose and provide relatively accurate quantification of leaf physiological performance. Scatterplots display post-fire data with colors representing FRED doses: blue $=$ control, yellow $=0.4 \mathrm{MJ} \cdot \mathrm{m}^{-2}$, orange $=0.8 \mathrm{MJ} \cdot \mathrm{m}^{-2}$, and red $=1.2 \mathrm{MJ} \cdot \mathrm{m}^{-2}$, and solid markers representing Pinus and open markers representing Larix. The solid and dotted lines represent predicted values for Pinus and Larix, respectively. Regression fits of mean values are in parentheses. Sub-plots are as follows: (a) average spectral reflectance of Pinus FRED dose groups from $\sim 0.4-2.5 \mu \mathrm{m}$; (b) dNDVI predicted from FRED four weeks post-fire (adapted from [8] to include a comparison with Larix); (c) $\mathrm{P}_{\mathrm{N}}$ predicted from dNDVI four weeks post-fire (adapted from [8] to include a comparison with Larix); and (d) chlorophyll fluorescence predicted from dPRI one week post-fire. 


\section{Discussion}

The strong relationship between $\mathrm{dNDVI}$ and $\mathrm{P}_{\mathrm{N}}$ observed in these fire dose-response experiments supports the methodology of [8] and further demonstrates that spectral indices have the potential to improve burn severity quantification through the monitoring of plant physiological metrics. While many studies have tested the utility of spectral indices for quantifying broad burn severity metrics (i.e., canopy cover, soil color, etc.) $[11,28,29,44]$, we were able link post-fire spectral indices and physiological responses in two functionally- and ecologically-distinct tree species.

While the links between vegetation physiological response and resulting post-fire reflectance are not well understood, this study provides evidence to suggest that these changes could be the result of significant photochemical and structural changes arising from fire-caused damage and stress. Previous remote sensing vegetation studies have identified that red reflectance from living vegetation is largely driven by photosynthetic pigments (such as chlorophyll and carotenoids) and near-infrared (NIR) reflectance is driven by structural features (leaf thickness, intercellular space, and dimensions) and other factors, such as nitrogen content [26,45]. Since the dPRI spectral index uses reflectance wavelengths mostly influenced by leaf pigments $[23,46]$, it is unsurprising that this index did not respond to the variations in photosynthesis that was not caused by differences in chlorophyll. In contrast, the use of both red and NIR reflectance in the calculation of dNDVI likely make this index a more integrative measure of changes in photosynthetic processes. The dNBR spectral index also uses a broader range of reflectance wavelengths than dPRI, but this index was not designed to assess physiological processes [30,47]. The NIR and shortwave infrared reflectance used by dNBR are apparently more influenced by water content and other compounds in a leaf than processes more directly related to photosynthesis [11]. While the overall spectral response was very similar between the two species, slight differences could be attributed to differences in leaf pigment composition or physiological response to stress [48].

Rather than chlorophyll fluorescence, changes in leaf structure could be driving the relationship between $\mathrm{P}_{\mathrm{N}}$ and dNDVI (Figure 4c). Changes in leaf structure have been observed to influence NIR in other vegetation types including herbaceous plants [49] and deciduous broadleaf trees [26]. High temperatures, such as those resulting from fires, can create structural deformations in leaf cell walls [19]. Similarly, model simulations suggest that the high air temperatures present during a fire could lead to extreme drops in water vapor pressure, causing cavitation in the foliage [50]. In our study, FRED doses caused clear damage to the seedling crowns and individual needles that were sampled for spectral and physiological measurements (Figure 1b-d). Generally, as the FRED dose increased, the proportion of needles with partial or complete scorch increased. Likewise, there were clear differences in the NIR reflectance between each FRED dose group (Figure 4a). Partial and/or complete heat damage could result in significant changes in both NIR reflectance and photosynthesis. In addition to chlorophyll and other pigments, photosynthesis requires adequate movement (conductance) of water, carbon dioxide $\left(\mathrm{CO}_{2}\right)$, nutrients, and plant biomolecules within and among cells. Although there was little evidence of increased water stress, estimates of leaf intercellular $\mathrm{CO}_{2}(\mathrm{Ci})$ indicated that the supply of $\mathrm{CO}_{2}$ limited photosynthesis in these trees. Leaf conductance to $\mathrm{CO}_{2}$ is highly influenced by leaf structure [51] and it is possible that we observed a strong relationship between dNDVI and $P_{N}$ because dNDVI is responding to changes in leaf structure. However, studies have identified other factors, such as foliar nitrogen content, which were not measured in this study, that could be driving the relationship between dNDVI and $\mathrm{P}_{\mathrm{N}}[26,45,52]$.

The strong relationship we observed between dNDVI and changes in $\mathrm{P}_{\mathrm{N}}$ at the leaf level does not necessarily mean dNDVI can now be directly applied to the characterization of landscape-scale burn severity and effects on tree physiology; several limitations are obvious. First, we used a small sample size to correlate physiological metrics to spectral indices. This sample size $(n=15-20)$ varied depending on how quickly foliage from each seedling died and was shed. Second, trees in landscape-scale fires are likely to be under more stress (i.e., water and/or nutrient stress) than the seedlings in this study and, therefore, the relationship between reflectance and $\mathrm{P}_{\mathrm{N}}$ potentially differs. Depending on environmental 
conditions, evergreen species can have periodic reductions in photosynthesis while light absorption remains constant $[53,54]$, which could lead to large errors if a constant $P_{\mathrm{N}}$-to-reflectance relationship is assumed. Multi-temporal field validation of the leaf-level dNDVI and $\mathrm{P}_{\mathrm{N}}$ data is needed. In addition, there is evidence that spectral properties observed at the leaf and branch level scale poorly to the landscape level due to effects resulting from species composition mixing, shadows, and non-vegetated areas $[25,27,55]$. Despite these challenges, studies have reduced scaling problems in tropical forests by using a fusion of LiDAR-derived canopy cover estimates and high spatial resolution $(<2 \mathrm{~m}$ pixel size) imagery [56]. Using this methodology, only spectral characteristics of canopy crowns are assessed, minimizing mixed pixel errors. A similar approach could be used with lower spatial resolution imagery (i.e., $30 \mathrm{~m}$ Landsat imagery) by integrating existing canopy cover products, such as the National Land Cover Database (NLCD) or the Landscape Fire and Resource Management Planning Tools Project (LANDFIRE) canopy cover products $[57,58]$ or LiDAR data, to quantify errors associated with variable canopy cover.

The temporal trajectories of all three indices over the duration of this study suggests that caution should be used when using these indices for long-term severity characterization (i.e., $>1$ year), as all indices returned to their baseline (pre-fire) values for both species at one year post-fire. This result has also been observed with studies using spectral indices to map burned area [36]. Specifically, burned area mapping accuracy derived from NBR and dNBR spectral indices was demonstrated to significantly decline in Southeastern U.S. ecosystems when satellite data more than two months post-fire was used [59]. While [59] were primarily concerned with an ecosystem dominated by Pinus palustris (longleaf pine), our findings agree with theirs in suggesting initial severity assessments may be preferred over extended assessments when using vegetation metrics (such as $\mathrm{P}_{\mathrm{N}}$ ) as the burn severity metric.

The results of this and the prior studies [8] demonstrate that at one month post-fire a clear dose-response relationship between FRED and ecophysiology metrics is apparent. This study demonstrated that at one year post-fire the surviving seedlings of the $0.4 \mathrm{MJ} \cdot \mathrm{m}^{-2}$ and $0.8 \mathrm{MJ} \cdot \mathrm{m}^{-2}$ treatments were not significantly different from the control. Therefore, the compelling question that future research could seek to elucidate is how long (i.e., between one month and one year) does it take for the control and treatment groups to converge? In terms of plants within natural ecosystems (i.e., not nursery grown), additional questions include how seasonality and other environmental stressors, such as droughts and insects, impact this recovery trajectory.

This study serves as an example of how spectral data can be used to assess physiological function following wildland fires. For instance, these data could improve estimates of carbon assimilation loss due to damaged or consumed leaf area. The strong relationships between tree physiology and remote sensing spectral indices provides a significant step towards improving the characterization of wildland fire severity and carbon cycle dynamics across fires and regions.

\section{Conclusions}

Results from two physiologically-different conifer seedlings highlight the potential of spectral indices to predict fire effects related to carbon processes. The dNDVI spectral index outperformed other spectral indices used for vegetation stress and burn severity characterization in regard to leaf $\mathrm{P}_{\mathrm{N}}$ quantification. In terms of how knowledge is advanced, this study provides the necessary spectral groundwork for the development of more sophisticated landscape-scale remote sensing assessments of how fires impact the terrestrial carbon cycle. Such research could help provide quantitative data on landscape fire vulnerability [60] to help decision-makers mitigate the impact of fires on the environment [61]. Although promising, future work is, however, needed to examine how these relationships scale from individual trees to forest stands. Other spectral indices, such as dNBR, have been shown to be good at capturing broad change metrics, such as amount of live vegetation, vegetation moisture content, and changes in areal extent of exposed soil [11,28]. However, as the widely-used Monitoring Trends in Burn Severity (MTBS) product [62] (delineated using dNBR) is 
usually the result of arbitrary thresholds [17], this research provides a path toward the development of more quantitative and mechanistic severity metrics.

Importantly, the survival of low and moderate FRED seedlings after one year post-fire confirms an immediate post-fire dose-response relationship and not short-term variation followed by delayed mortality. This further reaffirms that fire-induced mortality is more complex than the binary scenario where trees survive with no impacts below a certain temperature and duration threshold, and mortality occurs above the threshold [8]. In terms of burn severity for these two species, the return of all spectral indices from surviving seedlings to their pre-fire baselines at 52 and 54 weeks post-fire indicates that initial severity assessments conducted utilizing post-fire data from the same growing season as the fire may be more useful at quantifying severity (in terms of $\mathrm{P}_{\mathrm{N}}$ ) than extended assessments that utilize data from the following growing season. Further study is clearly needed to determine if these relationships hold for older, larger trees, and other plant species.

Supplementary Materials: The following are available online at www.mdpi.com/2072-4292/8/7/572/s1, Table S1: Pre- and post-fire spectral reflectance data for Pinus and Larix seedlings.

Acknowledgments: Seedlings were grown at the University of Idaho's Center for Forest Nursery and Seedling Research and combustion experiments were conducted within the Idaho Fire Initiative for Research and Education (IFIRE) combustion laboratory. This work was partially funded by the National Aeronautics and Space Administration (NASA) under award NNX11AO24G and the National Science Foundation under award IOS-1146751 to Dan Johnson. Partial support for Alan Talhelm was provided by the National Science Foundation under award DEB-1251441. Partial funding for this research for Aaron Sparks, Alistair Smith, and Crystal Kolden was provided by the National Science Foundation under Hazards SEES award DMS-1520873. Alistair Smith received partial support from the National Science Foundation award IIA-1301792. Aaron Sparks was additionally funded through the Idaho Space Grant Consortium. The views expressed in this paper are those of the authors and do not necessarily represent the views or policies of the U.S. Environmental Protection Agency.

Author Contributions: Aaron Sparks, Alan Talhelm, Alistair Smith, Dan Johnson and Kent Apostol conceived and designed the experiments; Aaron Sparks, Alistair Smith and Kent Apostol performed the experiments; Aaron Sparks and Kent Apostol analyzed the data; Aaron Sparks, Crystal Kolden, Alan Talhelm, Alistair Smith and Luigi Boschetti wrote the paper.

Conflicts of Interest: The authors declare no conflict of interest.

\section{References}

1. Van der Werf, G.R.; Randerson, J.T.; Giglio, L.; Collatz, G.J.; Kasibhatla, P.S.; Arellano, A.F., Jr. Inter-annual variability in global biomass burning emissions from 1997 to 2004. Atmos. Chem. Phys. 2006, 6, 3423-3441. [CrossRef]

2. Moritz, M.A.; Batllori, E.; Bradstock, R.A.; Gill, A.M.; Handmer, J.; Hessburg, P.F.; Leonard, J.; McCaffrey, S.; Odion, D.C.; Schoennagel, T.; et al. Learning to coexist with wildfire. Nature 2014, 515, 58-66. [CrossRef] [PubMed]

3. Barbero, R.; Abatzoglou, J.T.; Larkin, N.K.; Kolden, C.A.; Stocks, B. Climate change presents increased potential for very large fires in the contiguous United States. Int. J. Wildland Fire 2015, 10, 1071. [CrossRef]

4. Morgan, P.; Hardy, C.C.; Swetnam, T.W.; Rollins, M.G.; Long, D.G. Mapping fire regimes across time and space: Understanding coarse and fine-scale fire patterns. Int. J. Wildland Fire 2001, 10, 329-342. [CrossRef]

5. Keeley, J.E. Fire intensity, fire severity and burn severity: A brief review and suggested usage. Int. J. Wildland Fire 2009, 18, 116-126. [CrossRef]

6. Lentile, L.B.; Holden, Z.A.; Smith, A.M.S.; Falkowski, M.J.; Hudak, A.T.; Morgan, P.; Lewis, S.A.; Gessler, P.E.; Benson, N.C. Remote sensing techniques to assess active fire characteristics and post-fire effects. Int. J. Wildland Fire 2006, 15, 319-345. [CrossRef]

7. Lewis, S.A.; Wu, J.Q.; Robichaud, P.R. Assessing burn severity and comparing soil water repellency, Hayman Fire, Colorado. Hydrol. Process. 2006, 20, 1-16. [CrossRef]

8. Smith, A.M.S.; Sparks, A.M.; Kolden, C.A.; Abatzoglou, J.T.; Talhelm, A.F.; Johnson, D.M.; Boschetti, L.; Lutz, J.A.; Apostol, K.O.; Yedinak, K.M.; et al. Towards a new paradigm in fire severity research using dose-response experiments. Int. J. Wildland Fire 2016, 25, 158-166. [CrossRef]

9. Key, C.H. Ecological and sampling constraints on defining landscape fire severity. Fire Ecol. 2006, 2, 34-59. [CrossRef] 
10. Hudak, A.T.; Morgan, P.; Bobbitt, M.J.; Smith, A.M.S.; Lewis, S.A.; Lentile, L.B.; Robichaud, P.R.; Clark, J.T.; McKinley, R.A. The relationship of multispectral satellite imagery to immediate fire effects. Fire Ecol. 2007, 3, 64-90. [CrossRef]

11. Miller, J.; Thode, A. Quantifying burn severity in a heterogeneous landscape with a relative version of the delta Normalized Burn Ratio (dNBR). Remote Sens. Environ. 2007, 109, 66-80. [CrossRef]

12. Heward, H.; Smith, A.M.S.; Roy, D.P.; Tinkham, W.T.; Hoffman, C.M.; Morgan, P.; Lannom, K.O. Is burn severity related to fire intensity? Observations from landscape scale remote sensing. Int. J. Wildland Fire 2013, 9, 910-918. [CrossRef]

13. Birch, D.S.; Morgan, P.; Kolden, C.A.; Hudak, A.T.; Smith, A.M.S. Is proportion burned severely related to daily area burned? Environ. Res. Lett. 2014, 9, 064011. [CrossRef]

14. Sparks, A.M.; Boschetti, L.; Smith, A.M.S.; Tinkham, W.T.; Lannom, K.O.; Newingham, B.A. An accuracy assessment of the MTBS burned area product for shrub-steppe fires in the northern Great Basin, United States. Int. J. Wildland Fire 2015, 24, 70-78. [CrossRef]

15. Morgan, P.; Keane, R.E.; Dillon, G.K.; Jain, T.B. Challenges of assessing fire and burn severity using field measures, remote sensing and modelling. Int. J. Wildland Fire 2014, 23, 1045-1060. [CrossRef]

16. Hicke, J.; Asner, G.; Kasischke, E.; French, N.; Randerson, J.; Collatz, J.; Stocks, B.; Tucker, C.; Los, S.; Field, C. Postfire response of North American boreal forest net primary productivity analyzed with satellite observations. Glob. Chang. Biol. 2003, 9, 1145-1157. [CrossRef]

17. Kolden, C.A.; Smith, A.M.S.; Abatzoglou, J.T. Limitations and utilisation of Monitoring Trends in Burn Severity products for assessing wildfire severity in the USA. Int. J. Wildland Fire 2015, 24, 1023-1028. [CrossRef]

18. Butler, B.; Dickinson, M.B. Tree injury and mortality in fires: Developing process-based models. Fire Ecol. 2010, 6, 55-79. [CrossRef]

19. Michaletz, S.; Johnson, E.; Tyree, M. Moving beyond the cambium necrosis hypothesis of post-fire tree mortality: Cavitation and deformation of xylem in forest fires. New Phytol. 2012, 194, 254-263. [CrossRef] [PubMed]

20. Smith, A.M.S.; Talhelm, A.F.; Johnson, D.M.; Sparks, A.M.; Yedinak, K.M.; Apostol, K.G.; Tinkham, W.T.; Kolden, C.A.; Abatzoglou, J.A.; Lutz, J.A.; et al. Impacts of fire radiative energy density dose on lodgepole pine and western larch seedling physiology and mortality. Int. J. Wildland Fire 2016. [CrossRef]

21. Kremens, R.J.; Dickinson, M.B.; Bova, A.S. Radiant flux density, energy density and fuel consumption in mixed-oak forest surface fires. Int. J. Wildland Fire 2012, 21, 722-730. [CrossRef]

22. Hudak, A.T.; Dickinson, M.B.; Bright, B.C.; Kremens, R.L.; Loudermilk, E.L.; O’Brien, J.J.; Hornsby, B.S.; Ottmar, R.D. Measurements relating fire radiative energy density and surface fuel consumption-RxCADRE 2011 and 2012. Int. J. Wildland Fire 2015. [CrossRef]

23. Gamon, J.; Peñuelas, J.; Field, C. A narrow-waveband spectral index that tracks diurnal changes in photosynthetic efficiency. Remote Sens. Environ. 1992, 41, 35-44. [CrossRef]

24. Sellers, P.J.; Tucker, C.J.; Collatz, G.J.; Los, S.O.; Justice, C.O.; Dazlich, D.A.; Randall, D.A. A global 1 by 1 NDVI data set for climate studies. Part 2: The generation of global fields of terrestrial biophysical parameters from the NDVI. Int. J. Remote Sens. 1994, 15, 3519-3545. [CrossRef]

25. Friedl, M.A.; Davis, F.W.; Michaelsen, J.; Moritz, M.A. Scaling and uncertainty in the relationship between the NDVI and land surface biophysical variables: An analysis using a scene simulation model and data from FIFE. Remote Sens Environ. 1995, 54, 233-246. [CrossRef]

26. Ollinger, S.V. Sources of variability in canopy reflectance and the convergent properties of plants. New Phytol. 2011, 189, 375-394. [CrossRef] [PubMed]

27. Masek, J.; Hayes, D.; Hughes, M.; Healey, S.; Turner, D. The role of remote sensing in process-scaling studies of managed forest ecosystems. For. Ecol. Manag. 2015, 355, 109-123. [CrossRef]

28. Brewer, C.; Winne, J.; Redmond, R.; Opitz, D.; Mangrich, M. Classifying and mapping wildfire severity. Photogramm. Eng. Remote Sens. 2005, 71, 1311-1320. [CrossRef]

29. Cocke, A.; Fulé, P.; Crouse, J. Comparison of burn severity assessments using Differenced Normalized Burn Ratio and ground data. Int. J. Wildland Fire 2005, 14, 189-198. [CrossRef]

30. Key, C.H.; Benson, N.C. Landscape Assessment FIREMON: Fire Effects Monitoring and Inventory System, 1-55; USDA Forest Service General Technical Report, RMRS-GTR-164-CD; USDA Forest Service: Ogden, UT, USA, 2006. 
31. Wooster, M.J.; Roberts, G.; Perry, G.L.W.; Kaufman, Y.J. Retrieval of biomass combustion rates and totals from fire radiative power observations: FRP derivation and calibration relationships between biomass consumption and fire radiative energy release. J. Geophys. Res. Atmos. 2005, 110, D24. [CrossRef]

32. Kremens, R.J.; Smith, A.M.S.; Dickinson, M.B. Fire metrology: current and future directions in physics-based measurements. Fire Ecol. 2010, 6, 13-35. [CrossRef]

33. Smith, A.M.S.; Tinkham, W.T.; Roy, D.P.; Boschetti, L.; Kremens, R.J.; Kumar, S.; Sparks, A.M.; Falkowski, M.J. Quantification of fuel moisture effects on biomass consumed derived from fire radiative energy retrievals. Geophys. Res. Lett. 2013, 40, 6298-6302. [CrossRef]

34. Sackett, S.S.; Haase, S.M. Fuel loadings in southwestern ecosystems of the United States. In Proceedings of the Symposium on Fire on Madrean. Province Ecosystems; USDA Forest Service, General Technical Report RM-GTR-289. USDA Forest Service: Ogden, UT, USA, 1996; pp. 187-192.

35. Shea, R.W.; Shea, B.W.; Kauffman, J.B.; Ward, D.E.; Haskins, C.I.; Scholes, M.C. Fuel biomass and combustion factors associated with fires in savanna ecosystems of South Africa and Zambia. J. Geophys. Res. 1996, 101, 23551-23568. [CrossRef]

36. Trigg, S.; Flasse, S. Characterizing the spectral-temporal response of burned savannah using in situ spectroradiometry and infrared thermometry. Int. J. Remote Sens. 2000, 21, 3161-3168. [CrossRef]

37. Smith, A.M.S.; Wooster, M.J.; Drake, N.A.; Dipotso, F.; Falkowski, M.J.; Hudak, A.T. Testing the potential of multi-spectral remote sensing for retrospectively estimating fire severity in African Savannahs. Remote Sens. Environ. 2005, 97, 92-115. [CrossRef]

38. Roy, D.P.; Wulder, M.A.; Loveland, T.R.; Allen, R.G.; Anderson, M.C.; Helder, D.; Irons, J.R.; Johnson, D.M.; Kennedy, R.; Scambos, T.A.; et al. Landsat-8: Science and product vision for terrestrial global change research. Remote Sens. Environ. 2014, 145, 154-172. [CrossRef]

39. Rouse, J.W.; Haas, R.H.; Schell, J.A.; Deering, D.W.; Harlan, J.C. Monitoring the Vernal Advancements and Retrogradation of Natural Vegetation; NASA/GSFC, Final Report: Greenbelt, MD, USA, 1974; p. 137.

40. Glenn, E.P.; Cardann, P.; Thompson, T.L. Seasonal effects of shading on growth of greenhouse lettuce and spinach. Sci. Hortic. 1984, 24, 231-239. [CrossRef]

41. Schoettle, A.W.; Smith, W.K. Interrelationships among light, photosynthesis and nitrogen in the crown of mature Pinus contorta ssp. latifolia. Tree Physiol. 1999, 19, 13-22. [CrossRef] [PubMed]

42. Andrews, S.F.; Flanagan, L.B.; Sharp, E.J.; Cai, T. Variation in water potential, hydraulic characteristics and water source use in montane Douglas-fir and lodgepole pine trees in southwestern Alberta and consequences for seasonal changes in photosynthetic capacity. Tree Physiol. 2012, 32, 146-160. [CrossRef] [PubMed]

43. Bartlett, M.S. Properties of sufficiency and statistical tests. Proc. R. Soc. Lond. Ser. A 1937, 160, $268-282$. [CrossRef]

44. Lentile, L.B.; Smith, A.M.S.; Hudak, A.T.; Morgan, P.; Bobbitt, M.J.; Lewis, S.A.; Robichaud, P.R. Remote sensing for prediction of 1-year post-fire ecosystem condition. Int. J. Wildland Fire 2009, 18, 594-608. [CrossRef]

45. Peñuelas, J.; Filella, I. Visible and near-infrared reflectance techniques for diagnosing plant physiological status. Trends Plant Sci. 1998, 3, 151-156. [CrossRef]

46. Carter, G.; Knapp, A. Leaf optical properties in higher plants: linking spectral characteristics to stress and chlorophyll concentration. Am. J. Bot. 2001, 88, 677-684. [CrossRef] [PubMed]

47. García, M.J. Caselles Mapping burns and natural reforestation using thematic Mapper data. Geocarto Int. 1991, 6, 31-37. [CrossRef]

48. Wong, C.Y.; Gamon, J.A. Three causes of variation in the photochemical reflectance index (PRI) in evergreen conifers. New Phytol. 2015, 206, 187-195. [CrossRef] [PubMed]

49. Sinclair, T.; Schreiber, M.; Hoffer, R. Diffuse reflectance hypothesis for the pathway of solar radiation through LEAVES1. Agron. J. 1973, 65, 276-283. [CrossRef]

50. Kavanagh, K.; Dickinson, M.B.; Bova, A.S. A way forward for fire-caused tree mortality prediction: modeling a physiological consequence of fire. Fire Ecol. 2010, 6, 80-94. [CrossRef]

51. Flexas, J.; Barbour, M.; Brendel, O.; Cabrera, H.; Carriquí, M.; Díaz-Espejo, A.; Douthe, C.; Dreyer, E.; Ferrio, J.; Gago, J.; et al. Mesophyll diffusion conductance to CO2: An unappreciated central player in photosynthesis. Plant Sci. 2012, 193, 70-84. [CrossRef] [PubMed]

52. Gamon, J.A.; Field, C.B.; Goulden, M.L.; Griffin, K.L. Relationships between NDVI, canopy structure, and photosynthesis in three Californian vegetation types. Ecol. Appl. 1995, 5, 28-41. [CrossRef] 
53. Peñuelas, J.; Garbulsky, M.; Filella, I. Photochemical reflectance index (PRI) and remote sensing of plant CO2 uptake. New Phytol. 2011, 191, 596-599. [CrossRef] [PubMed]

54. Grace, J.; Nichol, C.; Disney, M.; Lewis, P.; Quaife, T.; Bowyer, P. Can we measure terrestrial photosynthesis from space directly, using spectral reflectance and fluorescence? Glob. Chang. Biol. 2007, 13, 1484-1497. [CrossRef]

55. Williams, D. A comparison of spectral reflectance properties at the needle, branch, and canopy level for selected Conifer species. Remote Sens. Environ. 1991, 35, 79-93. [CrossRef]

56. Asner, G.; Martin, R.; Anderson, C.; Knapp, D. Quantifying forest canopy traits: Imaging spectroscopy versus field survey. Remote Sens. Environ. 2015, 158, 15-27. [CrossRef]

57. Zhu, Z.; Vogelmann, J.; Ohlen, D.; Kost, J.; Chen, X.; Tolk, B.; Rollins, M. Mapping existing vegetation composition and structure for the LANDFIRE prototype project. In The LANDFIRE Prototype Project: Nationally Consistent and Locally Relevant Geospatial Data and Tools for Wildland Fire Management; USDA Forest Service Gen. Tech. Rep. RMRS-GTR-175; US Department of Agriculture, Forest Service, Rocky Mountain Research Station: Fort Collins, CO, USA, 2006; pp. 197-215.

58. Homer, C.G.; Dewitz, J.A.; Yang, L.; Jin, S.; Danielson, P.; Xian, G.; Coulston, J.; Herold, N.D.; Wickham, J.D.; Megown, K. Completion of the 2011 National Land Cover Database for the conterminous United States-Representing a decade of land cover change information. Photogram. Eng. Remote Sens. 2015, 81, 345-354.

59. Picotte, J.; Robertson, K. Timing constraints on remote sensing of wildland fire burned area in the southeastern US. Remote Sens. 2011, 3, 1680-1690. [CrossRef]

60. Smith, A.M.S.; Kolden, C.A.; Tinkham, W.T.; Talhelm, A.F.; Marshall, J.D.; Hudak, A.T.; Boschetti, L.; Falkowski, M.J.; Greenberg, J.A.; Anderson, J.W.; et al. Remote sensing the vulnerability of vegetation in natural terrestrial ecosystems. Remote Sens. Environ. 2014, 154, 322-337. [CrossRef]

61. Smith, A.M.S.; Kolden, C.A.; Paveglio, T.; Cochrane, M.A.; Mortitz, M.A.; Bowman, D.M.J.S.; Hoffman, C.M.; Lutz, J.; Queen, L.P.; Hudak, A.T.; et al. The science of firescapes: Achieving fire resilient communities. BioScience 2016, 66, 130-146. [CrossRef]

62. Eidenshink, J.; Schwind, B.; Brewer, K.; Zhu, Z.L.; Quayle, B.; Howard, S. A project for monitoring trends in burn severity. Fire Ecol. 2007, 3, 3-21. [CrossRef]

(C) 2016 by the authors; licensee MDPI, Basel, Switzerland. This article is an open access article distributed under the terms and conditions of the Creative Commons Attribution (CC-BY) license (http:/ / creativecommons.org/licenses/by/4.0/). 